\title{
ANatomia dos ÓRgãos Vegetativos E Histolocalização de Compostos Fenólicos E Lipídicos EM Porophyllum ruderale (ASTERACEAE) $^{1}$
}

\author{
Vegetative Organ Anatomy and Histolocalization of Lipids and Phenolics Compounds in \\ Porophyllum ruderale (Asteraceae)
}

FONSECA, M.C.M. ${ }^{2}$, MEIRA, R.M.S.A. ${ }^{3}$ e CASALI, V.W.D. ${ }^{4}$

\begin{abstract}
RESUMO - Porophyllum ruderale (Asteraceae) é uma erva ruderal e aromática conhecida popularmente como couve-cravinho. Na medicina popular, é utilizada como cicatrizante e antiinflamatória, antifúngica, antibacteriana, calmante, no combate à hipertensão arterial, no tratamento de leishmaniose, no tratamento de edemas e traumatismos, no tratamento de picada de cobra, doenças reumáticas e dores em geral. A atividade cicatrizante tem sido relacionada à presença de teores variáveis de compostos fenólicos do tipo taninos. Os objetivos do trabalho foram caracterizar as estruturas secretoras quanto à histolocalização dos compostos fenólicos e lipídicos e descrever a anatomia da raiz, do caule e da folha de couve-cravinho. De cinco plantas cultivadas, em fase de prefloração, foram coletadas a raiz, o caule e a folha, os quais foram fixados em FAA 50 ou em sulfato ferroso em formalina neutra tamponada (para observação de compostos fenólicos) e submetidos ao teste com Sudan III, visando a observação de compostos lipídicos. O laminário foi obtido utilizando-se metodologia tradicional. As raízes são tetrarcas, desenvolvem estrutura secundária e apresentam ductos secretores, os quais estavam presentes no córtex. O caule possui epiderme unisseriada recoberta por cutícula relativamente espessa; o parênquima cortical é intercalado com o colênquima subepidérmico; a medula é parenquimática; e os feixes são colaterais. Nos caules, os ductos também estavam presentes, porém somente nos jovens a reação para compostos fenólicos foi positiva. Nas folhas, o contorno das células epidérmicas é sinuoso e a epiderme é unisseriada e recoberta por cutícula delgada. São evidentes duas a três camadas de colênquima subepidérmico, e imerso no parênquima fundamental está o feixe colateral. No limbo foliar, foram observados ductos delimitados por várias camadas de células epiteliais, cujo conteúdo reagiu positivamente, indicando a presença de compostos lipídicos e fenólicos. Conclui-se que os ductos do caule e do limbo foliar são provavelmente as estruturas responsáveis pela secreção de tanino e que apenas os ductos do limbo foliar são responsáveis pela secreção de compostos lipídicos.
\end{abstract}

Palavras-chave: compostos fenólicos, compostos lipídicos, couve-cravinho, estruturas secretoras, Porophyllum ruderale.

\begin{abstract}
Porophyllum ruderale (Asteraceae) is a ruderal aromatic herb, known as "couve-cravinho". It is used in folk medicine for cicatrisation, as anti inflammatory, fungicide, anti bacterial, anti stress, to combat arterial hypertension, leishmaniosis, traumatism, antidote against snake poison, pain relief and rheumatism. Cicatrizing activity has been related with concentration of tannin, a type of phenolic compound. The objectives of this work were to characterize the secretory structures as to the histolocalization of the phenolic and lipid compounds and to describe the anatomy of root, stem and leaf collected from five cultivated plants, during the pre blossom
\end{abstract}

Recebido para publicação em 13.3.2006 e na forma revisada em 10.11.2006.

Doutora em Fitotecnia pela Universidade Federal de Viçosa - UFV, <mairacmf@yahoo.com.br>. ${ }^{3}$ D.S., Professora do Departamento de Biologia Vegetal da UFV, Avenida P.H. Rolfs s/n, 36570-000 Viçosa-MG; ${ }^{4} \mathrm{Ph} . \mathrm{D} .$, Professor do Departamento de Fitotecnia da UFV. 
phase, and fixed in FAA 50 or in solution of ferrous sulfate in formalin (for observation of the phenolic compounds). The slides were collected using traditional methodology. The roots are tetrarch, develop secondary structure, and have cortex ducts. Stem possesses relatively thick unisserial epidermis re-covered by cuticle; cortical parenchyma is interspersed with sub epidermic chollenchyma; the marrow is parenchematic and the beams are collateral. The ducts were present in the stems, but only in the young stem phenolic compound reaction was positive. In the leaves, the contour of the cells is winding, the epidermis consisting of a single layer of cells and covered with a thin cuticle; the two or three layers of subepidermic chollenchyma are evidenced and the collateral beam is immersed in the basic parenchyma. In the foliar limb, ducts were found to be delimited by several layers of epithelial cells whose content reacted positively indicating the presence of lipid and phenolic compounds. It was concluded that the stem and leaf ducts are probably the structures responsible for tannin secretion and only the leaf ducts are responsible for lipid compound secretion.

Keywords: phenolic compounds, lipid compounds, couve cravinho, secretory structures, Porophyllum ruderale.

\section{INTRODUÇÃO}

Porophyllum ruderale, espécie medicinal fonte de compostos fármaco-ativos, como o óleo essencial e o tanino, pertence à família Asteraceae. O potencial terapêutico dessa família deve ser investigado, pois existe conexão direta entre as propriedades físico-químicas dos compostos predominantemente lipofilicos e as atividades biológica e farmacológica. As plantas ricas em compostos fenólicos têm sido empregadas na medicina tradicional, no tratamento de diversas moléstias orgânicas e processos inflamatórios em geral (Haslam, 1996).

O gênero Porophyllum tem aproximadamente 28 espécies e está incluído na tribo Heleniae (Bremer, 1994). A característica marcante no gênero Porophyllum é a presença de estruturas secretoras glandulares translúcidas, localizadas longitudinalmente à margem da folha, prolongando-se ao interior e dispersas em toda a lâmina (Munz \& Keck, 1973). Tais estruturas foram anatomicamente descritas em Porophyllum lanceolatum (Monteiro, 1986; Monteiro et al., 1995). O conhecimento dos órgãos responsáveis pela síntese e pelo armazenamento dos princípios ativos das plantas é de fundamental importância nas decisões agronômicas de cultivo e pós-colheita (Reis \& Mariot, 2001).

O tipo e a posição da estrutura secretora de compostos químicos podem auxiliar na identificação da espécie, sendo utilizados como parâmetro no controle de qualidade farmacêutica (von Poser \& Mentz, 2001). As estruturas secretoras, comuns em muitos representantes da família Asteraceae, têm recebido atenção especial dos pesquisadores (Lersten \& Curtis, 1985, 1986, 1987, 1988; Monteiro, 1986, 1995; Poli, 1995; Arias, 1995), porém poucos foram os trabalhos desenvolvidos com espécies da família, considerando-se o elevado número destas (Judd et al., 1999). Assim, os objetivos do presente trabalho foram: descrever a anatomia de raiz, caule e folha, com ênfase na caracterização das estruturas secretoras, e proceder à histolocalização das estruturas secretoras de compostos fenólicos e lipídicos.

\section{MATERIAL E MÉTODOS}

Um exemplar de Porophyllum ruderale (Jacq.) Cassini foi coletado e incorporado ao acervo do herbário VIC (Herbário de Viçosa) sob o número 25169, sendo confirmada sua identidade taxonômica. Folhas, caules e raízes foram coletadas de cinco plantas cultivadas no canteiro de plantas medicinais do Grupo Entre Folhas de Plantas Medicinais, da Universidade Federal de Viçosa, no mês de maio de 2002, quando a planta se encontrava em fase de prefloração.

Folhas do quinto nó foram separadas nas partes apical, mediana e basal. Foram coletadas amostras de caule com diâmetro de aproximadamente $1 \mathrm{~cm}$ no ramo principal, $0,5 \mathrm{~cm}$ nas ramificações laterais e $0,2 \mathrm{~cm}$ do botão floral. Quanto às raízes, foram selecionados três diâmetros: raiz principal $(0,5 \mathrm{~cm})$, raiz 
lateral $(0,3 \mathrm{~cm})$ e raiz lateral $(0,1 \mathrm{~cm})$. As amostras foram cortadas em micrótomo de mesa e partes dos fragmentos foliares foram incluídos em parafina, sendo posteriormente cortadas em micrótomo rotativo com $8 \mathrm{Pm}$, de espessura. Visando a caracterização anatômica, fixaram-se as amostras em FAA 50 (Sass, 1951) e, em seguida, conservou-se em etanol $70 \%$ (Johansen, 1940). Cortes do material vegetal incluído em parafina foram corados com fuccina básica (quatro minutos) e azulde-astra (dois minutos) ou azul-de-toluidina, sendo as lâminas montadas em bálsamo-docanadá.

Para descrição histoquímica de compostos fenólicos, amostras vegetais foram fixadas em solução de sulfato ferroso em formalina (Johansen, 1940; Jensen, 1962) e cortadas em micrótomo de mesa. As lâminas foram montadas em gelatina glicerinada sem coloração posterior, para evidenciar compostos fenóicos (Jensen, 1962). Objetivando a descrição química de compostos lipídicos, outras amostras vegetais foram fixadas em FAA 50, cortadas em micrótomo de mesa, submetidas à reação com Sudan III glicerinado e Sudan Black B, sendo as lâminas montadas em gelatina glicerinada.

\section{RESULTADOS E DISCUSSÃO}

Constatou-se que as raízes em estrutura primária são tetrarcas e desenvolvem estrutura secundária precocemente, mesmo nas raízes de menor diâmetro avaliadas (Figura 1a). O córtex é parenquimático, com endoderme evidente mesmo no início da produção de tecidos vasculares secundários; com o desenvolvimento do crescimento secundário, a epiderme é substituída pela periderme (Figura 1b). Foram encontradas estruturas secretoras (ductos) nas raízes analisadas (Figura 1c, d), cujo conteúdo reagiu positivamente ao Sudan Black B, reagente utilizado para identificação de compostos lipídicos. A presença de estruturas secretoras parece ser uma característica comum das raízes de muitos representantes da família Asteraceae (Lersten \& Curtis, 1987).

No caule (Figura 2a, c), nota-se a presença de epiderme unisseriada recoberta por cutícula relativamente espessa, com estômatos na região que recobre o parênquima clorofiliano (Figura 2d). O parênquima clorofiliano cortical é intercalado com o colênquima subepidérmico
(Figura 2d); a medula é parenquimática e os feixes vasculares são colaterais (Figura 2a, c). No córtex, próximo aos feixes vasculares, há pequenos ductos secretores delimitados por uma camada de células epiteliais de paredes finas e núcleo volumoso (Figura 2a, c, e). O conteúdo desses ductos reagiu positivamente ao sulfato ferroso (Figura 2a), indicando a presença de compostos fenólicos. Apesar de a espécie ser conhecida pela produção de taninos na folha, provavelmente os ductos dos caules jovens também produzam taninos, já que reagiram positivamente ao teste de compostos fenólicos. Estudos sobre raízes e caules são pouco freqüentes em Asteraceae. Nessa família, estruturas secretoras têm sido consideradas de valor taxonômico, seja pela diversidade dos tipos, pela posição em que ocorrem ou pela natureza da secreção (Castro et al., 1997; Solereder, 1908; Lersten, 1985). Porophyllum ruderale está incluída na tribo Helenieae (Bremer, 1994), assim como Tagetes patula, onde ductos secretores foram observados nos órgãos subterrâneos (Poli et al., 1995).

No limbo foliar, o contorno das células epidérmicas é sinuoso tanto na face adaxial como na abaxial (Figura 3b). A epiderme unisseriada é formada por células de paredes sinuosas, resultado que concorda com o observado por Arias (1995), e recoberta por cutícula delgada, característica encontrada em outras compostas (Sajo \& Menezes, 1994), em que os tricomas estão ausentes. Na nervura mediana, são evidentes duas a três camadas de colênquima subepidérmico, e imerso no parênquima fundamental está o feixe colateral. A folha é dorsiventral (Figura 3a), característica comum entre as Asteraceae. Estruturas secretoras são visíveis à vista desarmada e encontram-se distribuídas por toda a lâmina foliar, inclusive na margem (Figura 3c). Anatomicamente, são caracterizadas por várias camadas epiteliais que delimitam o lume alongado (Figura 3d), diferentemente das estruturas presentes no caule, delimitadas por apenas uma camada de células (Figura 2e). O lume de cavidades e ductos é isodiamétrico (ou esférico) nas cavidades e consideravelmente alongado em um único plano nos ductos (Cutter, 1978; Fahn, 1979; Metcalfe, 1983). Como o lume observado é alongado em cortes longitudinais, essas estruturas foram denominadas ductos. Entretanto, estruturas semelhantes foram descritas na 

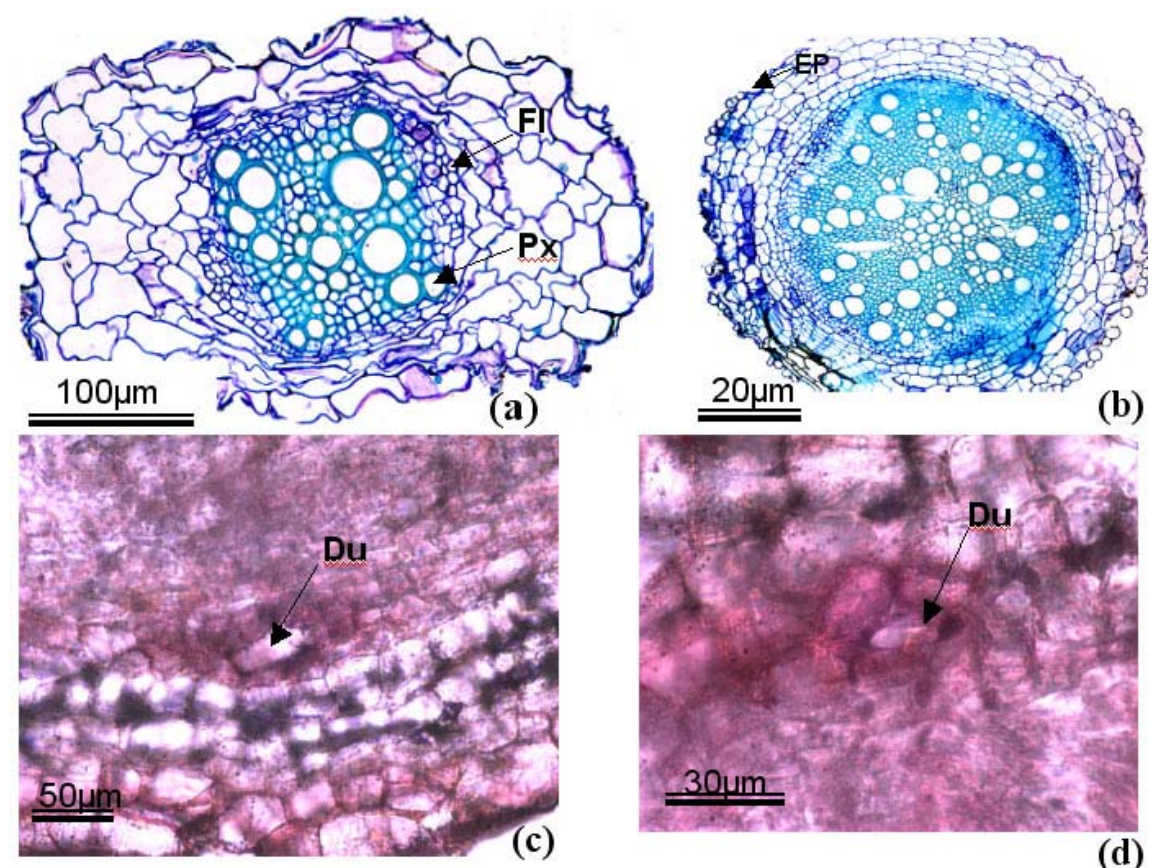

Figura 1 - Cortes transversais da raiz de Porophyllum ruderale, em que (a) e (b): corados com azul-de-toluidina; e (c) e (d) submetidos ao Sudan Black B, evidenciando os ductos secretores.

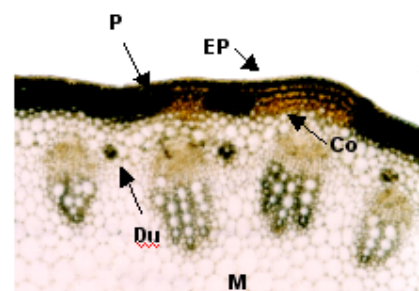

$200 \mu \mathrm{m}$

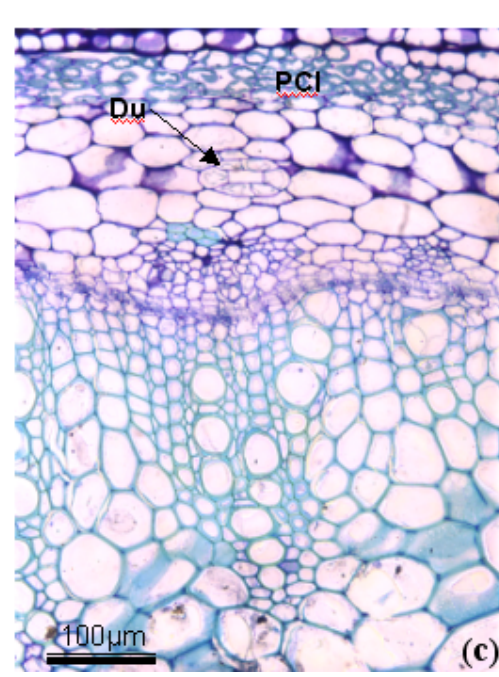

(c)

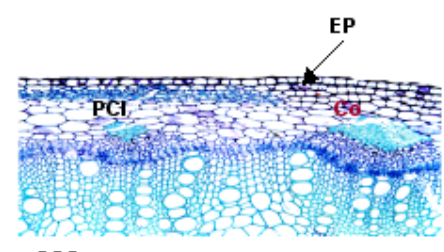

(b)

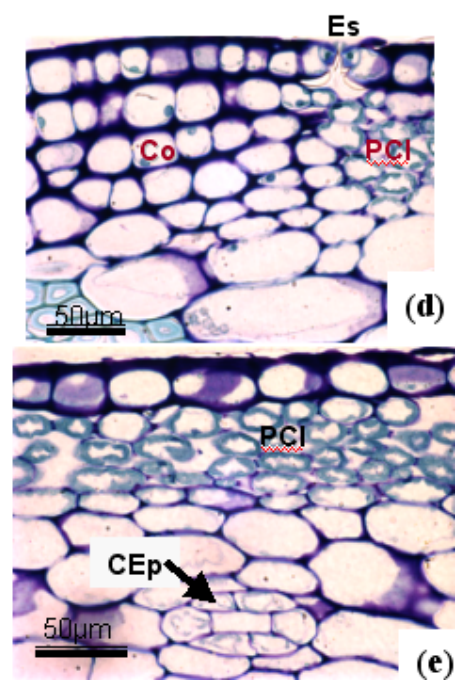

Figura 2 - Cortes transversais do caule de Porophyllum ruderale, em que (a) fixado em sulfato ferroso; e de (b) a (e) corados com azul-de-toluidina. 

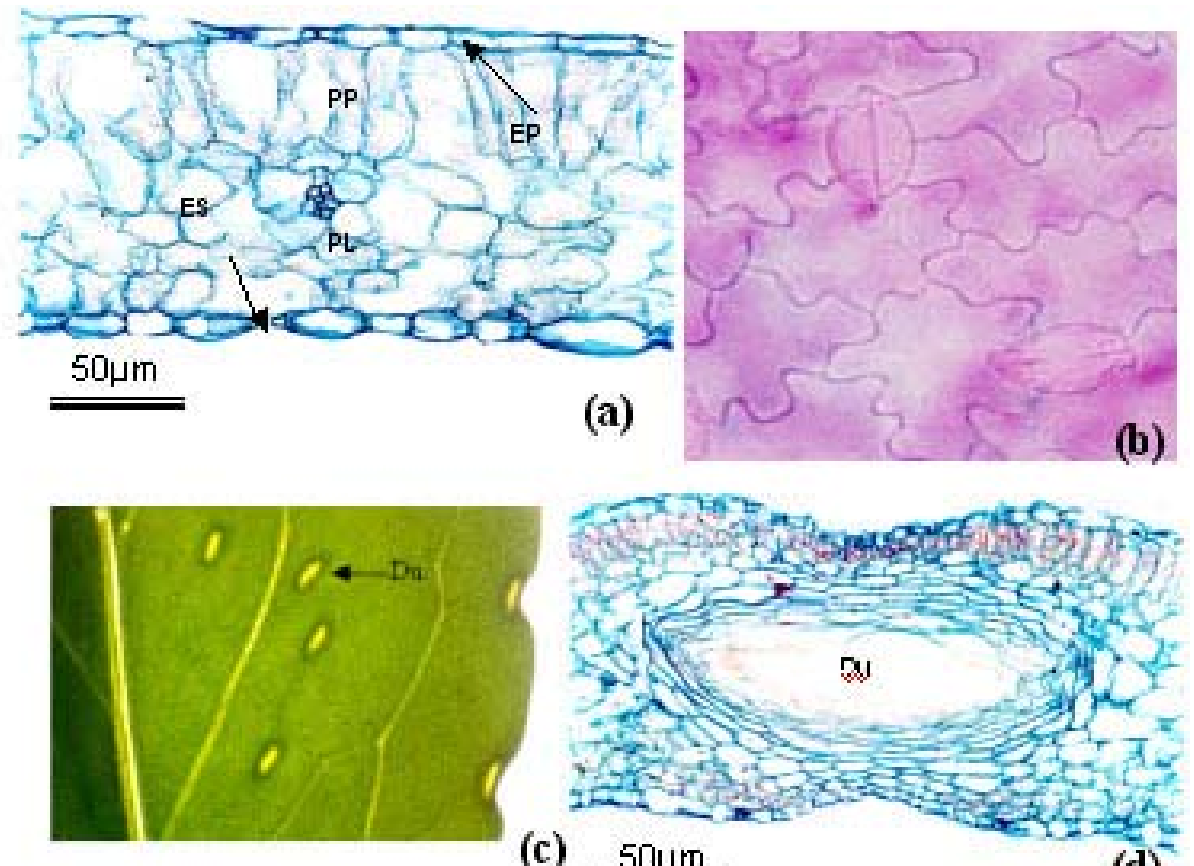

(c)

(d)
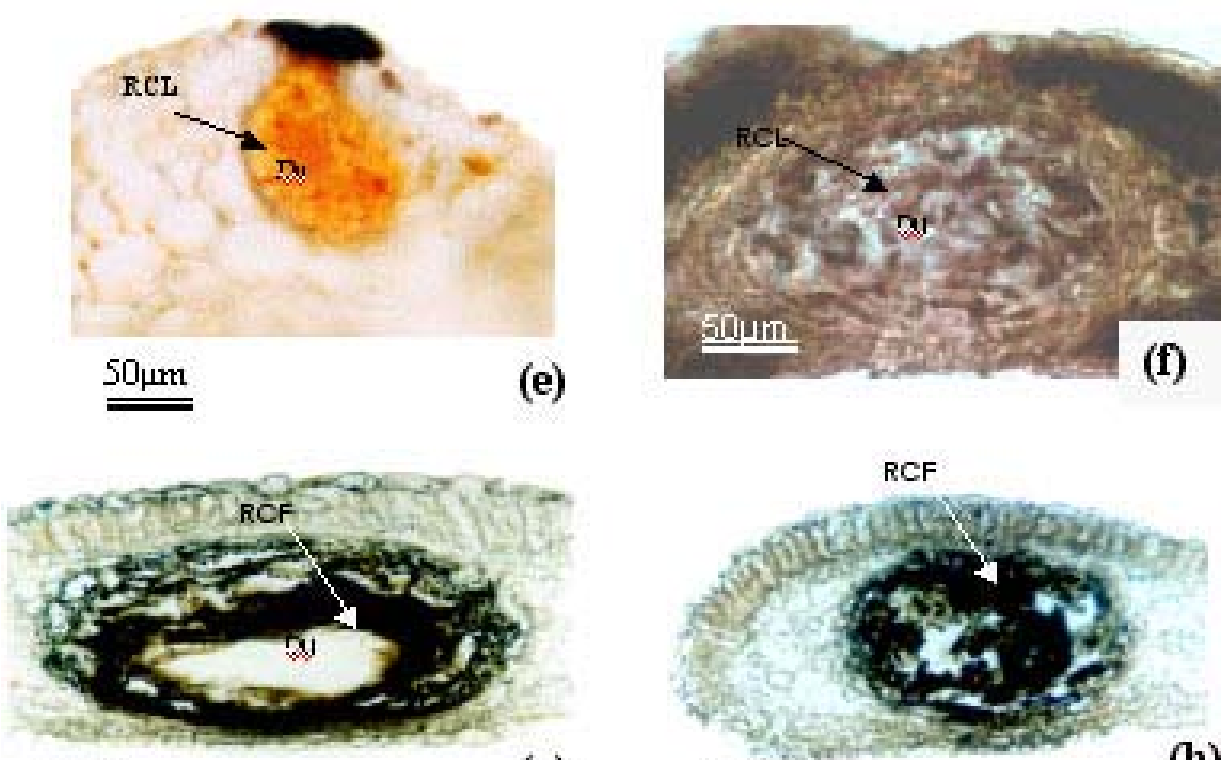

$50 \mu \mathrm{m}$

(g)

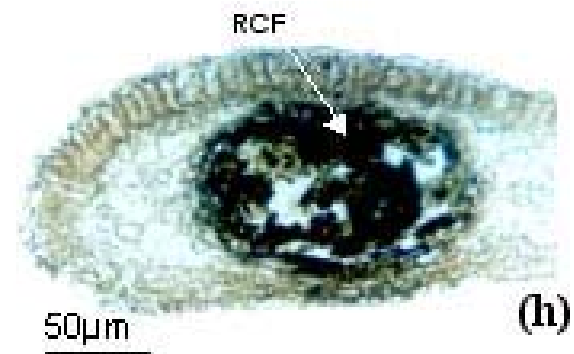

PX - protoxilema; Fl - floema; XS - xilema secundário; Co - colênquima; EP - epiderme; Du - ducto; $\mathrm{PCl}$ - parênquima clorofiliano; ES - estômato; PP - parênquima paliçádico; PL - parênquima lacunoso; CEp - células epiteliais; M- medula; RCL - reação indicando compostos lipídicos; RCF - reação indicando compostos fenólicos.

Figura 3 - Folhas de Porophyllum ruderale, em que: (a) corte transversal, corado com azul-de-toluidina; (b) face adaxial do limbo foliar; (c) vista superficial da folha; (d) corte longitudinal da folha, destacando o ducto foliar; (e) corte transversal do limbo foliar submetido ao Sudan III glicerinado, evidenciando compostos lipídicos; (f) corte longitudinal do ducto foliar submetido ao Sudan Black B, evidenciando compostos lipídicos; (g) corte longitudinal da lâmina foliar fixado com sulfato ferroso, evidenciando compostos fenólicos; e (h) corte transversal da margem foliar fixado com sulfato ferroso, evidenciando compostos fenólicos. 
folha de Porophylum lanceolatum e denominadas cavidades alongadas (Monteiro, 1986). Lersten \& Curtis (1988) adotaram o termo "reservatórios" em ambos os tipos de estruturas secretoras (ductos e cavidades), considerando não o comprimento, mas apenas a estocagem de secreções nestas estruturas. Os ductos visualizados em Porophylum ruderale, marginal ou laminar, localizam-se em área intensamente vascularizada (Figura 3c) e se posicionam próximos à epiderme. As cavidades secretoras estão presentes na forma de pontos translúcidos (transparentes) ou estrias finas em folhas (Metcalfe \& Chalk, 1950), tendo sido identificadas em vários gêneros da família Asteraceae, inclusive no gênero Porophyllum (Monteiro, 1986; Monteiro et al., 1995).

De acordo com os testes histoquímicos, tanto em material fresco quanto em fixado os ductos secretam substância de natureza mista, contendo compostos lipídicos (Figura 3e, f) e fenólicos (Figura 3g, h). Em trabalho realizado por Fonseca (2001), foi verificado que as folhas de Porophyllum ruderale contêm óleo essencial e tanino. Rodriguez \& Mabry (1977) afirmam que em três espécies de Porophyllum é muito comum a presença de monoterpenos voláteis, constituintes majoritários do óleo essencial de Porophyllum ruderale. Neste estudo, constatouse, em testes histoquímicos, que compostos fenólicos e lipídicos estão presentes nas folhas de Porophylum ruderale, concordando com o resultado observado por Monteiro (1986) em Porophyllum lanceolatum.

Conclui-se que as únicas estruturas secretoras verificadas no presente trabalho foram os ductos secretores formados por uma camada epitelial nos caules jovens e nas raízes, bem como por várias camadas nas folhas. Essas estruturas reagiram positivamente ao teste de compostos fenólicos, com exceção das raízes. Sugere-se que os ductos presentes no caule e no limbo foliar sejam os responsáveis diretos pela síntese de taninos na espécie. Os óleos essenciais provavelmente são sintetizados apenas nos ductos foliares, nessa fenofase, pois a reação de compostos lipídicos foi positiva somente neste órgão.

\section{AGRADECIMENTOS}

Às técnicas Rosane Cruz Portugal e Zilda Alzira Soares, pelo auxílio na confecção do laminário; e ao Conselho Nacional de Desenvolvimento Científico e Tecnológico (CNPq), pela bolsa concedida ao primeiro autor.

\section{LITERATURA CITADA}

ARIAS, R. L. Estudo morfoanatômico em espécies de Lynchnophora Mart. (Asteraceae) dos campos a rupestres do Brasil. 1995. 89 f. Tese (Doutorado em Botânica) Universidade de São Paulo, São Paulo, 1995.

BREMER, K. Asteraceae: cladistics and classification. Portland: Timber Press, 1994. 752 p.

CASTRO, M. M.; LEITÃO-FILHO, H. F; MONTEIRO, W. R. Utilização de estruturas secretoras na identificação dos gêneros de Asteraceae de uma vegetação do cerrado. R. Bras. Bot., v. 20, p. 163-174, 1997.

CUTTER, E. G. Plant anatomy. Cells and tissues. 2.ed. London: Edward Arnold, 1978. Part I.

FAHN, A. Secretory tissues in plants. Oxford: Academic Press, 1979.

FAHN, A. Plant anatomy. 3.ed. Oxford: Pergamon Press, 1982.

FONSECA, M. C. M. Crescimento, composição do óleo essencial, teores de óleo e tanino em Porophyllum ruderale (Jacq.) Cassini. 2001. 68 f. Dissertação (Mestrado em Fitotecnia) - Universidade Federal de Viçosa, Viçosa, 2001.

HASLAM, E. Natural polyphenols (vegetable tannins) as drugs and medicines: possible modes of action. J. Natural Prod., v. 59, p. 205-215, 1996.

JENSEN, W. A. Botanical histochemistry: principles and practice. San Francisco: W. H. Freeman \& Co., 1962. 408 p.

JOHANSEN, D. A. Plant microtechnique. New York: McGraw-Hill Book Co, 1940. 523 p.

JUDD, W. S. et al. Plant systematics - a phylogenetic approach. Massachusetts: 1Sinaver Associates, Publishers Sunderland, 999. $464 \mathrm{p}$.

LERSTEN, N. R.; CURTIS, J. D. Distribution and anatomy of hidathodes in Asteraceae. Bot. Gazette, v. 146, p. 106-114, 1985.

LERSTEN, N. R.; CURTIS, J. D. Tubular cavities in white snakeroot, Eupatorium rugosum (Asteraceae). Am. J. B., v. 73, p. 1016-1021, 1986.

LERSTEN, N. R.; CURTIS, J. D. Internal secretory spaces in Asteraceae: a review and original observations on Conyza canadensis (Tribe asteraceae). La Cellule, v. 74, p. 179-196, 1987. 
LERSTEN, N. R.; CURTIS, J. D. Secretory reservoirs (ducts) of two kinds in giant ragweed (Ambrosia trifida Asteraceae). Am. J. Bot., v. 75, p. 1313-1323, 1988.

\section{METCALFE, C. R.; CHALK, L. Anatomy of the}

Dicotyledons: leaves, stem and wood in relation to taxonomy with notes one economic uses. Oxford: Clarendon Press, 1950. $2 \mathrm{v}$

\section{METCALFE, C. R.; CHALK, L. Anatomy of the}

Dicotyledons: wood, structure and conclusion of the general introduction. 2.ed. Oxford: Clarendon Press, 1983. v. 2.

MONTEIRO, W. R. Estruturas secretoras da folha de Porophyllum lanceolatum DC. (Asteraceae): estudos morfológicos, histoquímicos e ultra-estruturais. 1986. $63 \mathrm{f}$. Tese (Livre-Docência em Botânica) - Universidade de São Paulo, São Paulo, 1986.

MONTEIRO, W. R.; CASTRO, M. M; FAHN, A.

Observations on development of the foliar secretory cavities of Porophyllum lanceolatum (Asteraceae). Nordic J. Bot., v. 15 , p. 69-76, 1995.

MUNZ, P. A; KECK, D. D. A California flora. Berkeley: University of California Press, 1973. 211 p.
POLI, F.; GIANNI, S.; BRUNI, A. Distribuition of internal secretory structures in Tagetes patula (Asteraceae). Nordic J. Bot., v. 15, p. 197-205, 1995.

REIS, M. S.; MARIOT, A. Diversidade natural e aspectos agronômicos de plantas medicinais. In: SIMÕES, C. M. O. et al. Farmacognosia da planta ao medicamento. Porto Alegre: Universidade Federal do Rio Grande do Sul, 2001. p. $10-12$.

RODRIGUEZ, E.; MABRY, T. J. Tagetae chemical review. In: HEYWOOD, C.V.H. (Ed.) The biology and chemistry of the Compositae. London: Academic Press, 1977.

SAJO, M. G.; MENEZES, N. L. Considerações sobre a anatomia foliar de espécies de Vernonia Screb. (Compositae) da Serra do Cipó, MG. Naturalia, v. 19, p. 173-183, 1994.

SASS, J. E. Botanical microtechnique. 2.ed. Ames: The Iowa State College Press, 1951.

SOLEREDER, H. Systematic anatomy of the dicotyledons. Oxford: Clarendon Press, 1908. 1182 p.

von POSER, G. L.; MENTZ, L. A. Diversidade biológica e sistemas de classificação. In: SIMÕES, C. M. O. et al.

Farmacognosia da planta ao medicamento. Porto Alegre: Universidade Federal do Rio Grande do Sul, 2001. p. 63-76. 